\title{
Fostering Entrepreneurial Mentoring Culture for Sustainable Leadership Performance in Nigeria: Evidence from Selected SMEs in Ilorin Metropolis
}

http://doi.org/10.21272/bel.4(3).73-80.2020

Bolatito Amudat Brimah, ORCID: https://orcid.org/0000-0003-3272-0304

$\mathrm{PhD}$, Head of Department, Department of Business Administration, Faculty of Management Sciences, Al-Hikmah University, Ilorin, Nigeria

Rukayat Oloruntoyin Rabiu, ORCID: https://orcid.org/0000-0001-9781-039X

M.Sc., Part Time Lecturer, Department of Business Administration, Faculty of Management Sciences, AlHikmah University, Ilorin, Nigeria

Ayodeji Gbenga Bamidele, ORCID: https://orcid.org/0000-0003-1114-0714

$\mathrm{PhD}$, Course Facilitator, Department of Business \& Entrepreneurship, School of Business and Governance, Kwara State University, Malete

Musa Olojeola Sheu, ORCID: https://orcid.org/0000-0001-7721-0311

B.Sc, Department of Business Administration, Faculty of Management Sciences, Al-Hikmah University, Ilorin, Nigeria

\begin{abstract}
The human resources are the most important resources an organization can boast of in the $21^{\text {st }}$ century, since it ensures the efficient and effective utilization of other types of resources, hence their continuous development. One of the ways of developing human resources is through entrepreneurial mentoring. Mentoring is among the few tools needed for preparing tomorrows' skilled employees and is also used to strengthen organizational capabilities, intelligence, build organization knowledge, and sustain the organization competitive advantage. The dynamic career environment heightens the need for entrepreneurs engaging other people in their career and personal development. This study examined the effect of entrepreneurial mentoring on performance of SMEs in Kwara State. Data for the study were obtained from primary sources with the aid of a structured questionnaire. The research design adopted was a descriptive survey design which was also cross sectional in nature. Data collected were analyzed and hypotheses were tested using Analysis of Variance (ANOVA) at 5\% level of significance. Findings revealed that psychosocial mentoring support, career mentoring support and role modelling mentoring support all had significant relationship with SMEs performance as all their respective $\mathrm{p}$ values were less than 0.05 alpha values. Effective and efficient mentorship programs tend to raise entrepreneurial outcomes among upcoming entrepreneurs operating SMEs. Based on the findings of this study, the study concludes that there is significant relationship between psychosocial mentoring support and SMEs performance; there is also significant relationship between career mentoring support and SMEs performance, there is significant relationship between role modeling mentoring support and SMEs performance. The study recommends that SMEs owners must be steadfast in fostering an entrepreneurial mentoring culture within the organisation. Also, SMEs owners must be steadfast in continuously providing sponsorship, coaching, exposure, visibility, protection and providing challenging assignments to employees. Also, succession planning must be continually improved and sustained.
\end{abstract}

Keywords: Entrepreneurial Mentoring, Culture, Leadership, Performance, SMEs, Nigeria.

JEL Classification: L26, L25, M14.

This work is licensed under a Creative Commons Attribution 4.0 International License

Cite as: Brimah, B. A., Rabiu, R.O., Bamidele, A.G., Sheu, M.O. (2020). Fostering Entrepreneurial Mentoring Culture for Sustainable Leadership Performance in Nigeria: Evidence from Selected SMEs in Ilorin Metropolis. Business Ethics and Leadership, 4(3), 73-80. http://doi.org/10.21272/bel.4(3).73-80.2020.

(C) The Authors, 2020. This article is published with open access at Sumy State University. 


\section{Introduction}

Social entrepreneurship uses market-based methods and techniques for solving society's and/or community's problems. It represents a key driver for improving the quality of life of people and communities, considering the economic and social accelerated changes and the survival of companies in a turbulent and competitive global environment. The disadvantaged people's quality of life is often affected due to their defective material and financial resources, which can have a positive impact on their lives when they are turned into a state of well-being or a negative effect when they are discriminated against they feel insecure. The paper contributes to a better understanding of the two concepts: social entrepreneurship and quality of life. Also, it shows that social entrepreneurship and quality of life are two related concepts as the first one has a positive impact on the second one through various actions, such as ensuring the primary material conditions, creating jobs for disadvantaged people, increasing the level of education, improving the health system, environmental protection, etc.

From a practical point of view, the TOMS business model can be replicated by other companies by disseminating its acceptable practices, which must be done through various sources, to have a large addressability area. Firstly, one dissemination method is through modern communication instruments, especially in the online environment, enabling quick access, real-time updating of information, and transparency. The second method is to organize training, seminars, and other actions with specific themes to develop an organizational culture based on social responsibility values and principles. Direct interaction between the speakers and the target audience creates opportunities for face-to-face debates and the participants may be potential social entrepreneurs. Simultaneously, inviting decision-makers who have been directly involved in such actions is beneficial due to their power of example and experience, which are inspirations sources and successful role models for participants. Thirdly, acceptable practices can be promoted through opinion leaders involved in community life because they gain the community members' trust. Fourthly, publications (such as impact reports) are also a powerful communication tool through their visual content, which significantly impacts the knowledge transfer's potential beneficiaries. It can be said that the TOMS strategy has beneficial effects, materialized in increasing the confidence for both investors and employees, by protecting and maximizing the company's good-will, adopting a socially responsible behavior within their organization, reducing expenses, and losses by using resources efficiently. Further research may explore the influence of quality of life on social entrepreneurship, namely that various elements of quality of life can stimulate or discourage social entrepreneurship initiatives.

Fundamentally, the goal of mentoring is personal and professional development, with mentors becoming trusted role models. In this regard, mentees look up to mentors for counsel. Effective communication, which is a face-to-face interactive session, must be sustained over a while. The mentor, who is a person who is perceived to have a more excellent relevant knowledge, wisdom, or experience and the mentee, who is a person perceived to have less, must come in close contact in the mentoring process. Mentoring covers the activities often designed and encouraged by management to develop its personnel and ensure that they improve and maintain their competitive advantage. Organizations need effective managers and employees to achieve their objectives and cannot succeed without their personnel efforts and better performance (MindTools, 2014). Various setbacks have been identified as the factors that contribute to psychological mentoring and career mentoring in SMEs' performance in an organization such as education, experience, entrepreneurial culture, and the need for an entrepreneurial team that impacts the entrepreneur's performance. Lack of essential business management and entrepreneurship skills is a significant drawback in the SME sector's growth and development, as pointed out in Sessional Paper No 2 (GOK, 2005).

Objective of the Study. The objective of the study is directed to:

$>$ examine the relationship between psychological mentoring support and SMEs performance;

$>$ investigate the relationship between career mentoring support and SMEs performance;

$>$ determine the relationship between role modeling support and SMEs performance.

\section{Literature Review}

\subsection{Conceptual Clarifications}

Definitions of Entrepreneurship. The concept of entrepreneurship has a complex tradition within economic theory and any attempt to formulate a succinct description will inevitably exclude a valuable element of this history (Bygrave, 1989). It fundamentally implies that there are almost as many definitions of entrepreneurship as scholars and books regarding this subject (Boyd, 1998). McClelland (1961) defined entrepreneurship from 
the concept of "achievement of needs". It is a dynamic process created and managed by an individual, the entrepreneur, who strives to exploit economic innovation to create new value in the market toward achieving a particular need. Ototiki (1987) looked at entrepreneurship in the form of the determinant of its development and creation in the new industrial country or analysis that showed education, family background capital outlay and level of previous experience and level of exposure associated with its human development. Bygrave and Hofer (1999) defined entrepreneurship as "a process of creating a new organization and pursuing it". According to them, the process of entrepreneurship involves all functions, activities, and actions associated with the perceiving opportunities and the creation of organizations to pursue them. Timmons \& Spinell (2004) defined entrepreneurship "as the ability to create and build something from practically nothing". Entrepreneurship as an innovative activity (Schumpeter, 1982) usually involves adopting new products, processes, new technologies, new enterprises and methods.

Mentorship. Arogundade (2000) conceptualizes a mentor as an individual that drives the facilitation process that seeks to accelerate personal and professional growth through activities such as knowledge sharing learned over the years. It goes to aver that mentoring can be described as a process that is built on a personal developmental relationship between a more experienced or more knowledgeable person and less experienced ones. The more experienced, educated, exposed and most importantly knowledgeable mentor shares a close, developmental relationship with the mentee. Mentoring no doubt guarantees and facilitates a process where the mentor can avail him /herself of the full range of superior experience, knowledge, skills, or status of the other partner in all human endeavors. The Institute of Business Advisors South Africa (IBA) perceived mentoring as an ongoing, long-term business counseling relationship that subsists between an experienced business advisor and client, covering a diverse range of topics as a business develops. Furthermore, Chebii (2017) conceives mentoring as a process that brings into close contact matured, experienced and knowledgeable managers in close contact with younger employees on a one on one basis. The wisdom and experience of the mature managers are shared and brought to bear in this regard. All these confirm that mentoring is a method growing in use for establishing the relationship between junior and senior employees, a method gaining popularity in facilitating both employee and management development in the organization

Crompton (2016) posited that mentoring is a set of tailor-made advice and incentive that more experienced staff, in an innovative way, can offer less experienced members in a plethora way and on a range of competencies. Several factors have been identified in the definitions of mentoring. These factors indicate that the mentoring relationship is a long-term relationship that focuses on learning and developing. Ojedokun (2013) viewed mentoring as a process by which persons of superior rank and prestige instruct, counsel, guide, and facilitate the intellectual and/or career development of persons identified as protégées. Mentoring is a close, developmental relationship between two people in which a partner willingly avails him/herself of the full range of superior experience, knowledge, skills, or status of the other partner in all spheres of human endeavor. Entrepreneurial mentoring will include all of these factors. Ayer (2010) believes that entrepreneurial mentoring aims to allow the mentees to be guided by experienced mentors, thereby enabling mentees to develop their skills and abilities. The entrepreneurial experience will be improved as a result. The objective of the mentoring process is to assist the mentees in acquiring specific skills or competencies.

Mentoring Functions. Entrepreneurs account for a substantial part of enterprises' performance in today's global and local economy. Earlier Schumpeter (1934) emphasizes the role of the entrepreneur as a prime cause of economic development. The fundamental functions upon which an entrepreneur can carry out mentoring activities are as follows:

Career Mentoring Functions. As the name implies, functionally this type is one that fundamentally aids the advancements of careers of employees or mentees involved. Efforts and activities such as sponsorship, coaching, exposure, visibility, protection and providing challenging assignments are usually geared to develop and mentor employees, thereby facilitating career advancement (Kram, 1985). Ayer (2010) opines that entrepreneurs are not careered employees; a description which culminated in this research focusing on the protégés' business advancement or promotion which was taken as an entrepreneurial outcome. Career mentoring functions such as coaching, sponsorship, exposure, and protection result into objective outcomes Allen, Day, \& Lentz (2011). Further, Allen et al. (2011) indicated that, the behaviors associated with career mentoring are highly focused on preparing protégé's for advancement therefore reasoning that career mentoring may relate more highly to objective career outcomes than does psychosocial mentoring. This study adapted the definition of objective entrepreneurial outcomes from that of objective career success. Allen et al. (2011) concluded that the most popular description of career mentoring was the mentor committed to the mentees' upward mobility and provided support. 
> Psychosocial Mentoring Functions. Psychosocial functions help a protégé's personal development by relating to him or her on a more personal level, according to Kram (1985). Further, Allen, et al. (2011) found the most popular description of psychosocial functions was that of mentors providing personal counsel. Kram (1985) indicated that psychosocial functions enhance the protégé's sense of competence, clarity of identity, and effectiveness in the job through role modeling, counseling, and friendship.

$>$ Classic mentoring/Role Model and Objective entrepreneurial outcomes. Allen \& Eby (2003) described the 'classic' model of mentoring as a relationship between an experienced adult and an unrelated young person, characterized by trust, reciprocity, challenge, support and control. According to Allen, Eby \& Lentz (2006), most of the examined studies have focused on the 'classic' style of mentoring as a one-to-one relationship between an older adult and a young person. Allen, Eby \& Lentz (2006) further emphasize that "Classic mentoring" features one to one relationships between a more senior or experienced individual and a less senior experienced individual. This type of mentoring undoubtedly is highly interactive, considering that it entails a one-to-one between the mentor and mentee. Therefore, it is guided by developmental learning based on the premise that the participants will have reasonably frequent contact and sufficient interactive time together (Allen, Eby \& Lentz, 2006). In 'classic' forms of mentoring, mentors are successful adults, often of the same gender and ethnic group as the mentee (Allen, Eby \& Lentz, 2006).

Small and Medium Scale Enterprise (SMEs). Ayaggari, Beck \& Demirguc-Kunt (2003) contend that SMEs' definition varies according to context, author and countries. The conceptualization of SMEs' concept depends mostly on a country's level of development (Nnana, 2002), making it difficult to have a universal definition of what an SMEs are. However, it is quick to note that some common indexes of the definition, such as the number of employees, value of assets, and turnover. Grace and Tomola (2008), relying on the computerization of SMEs according to the Small and Medium Industries Equity Investment Scheme (SMIEIS) in Nigeria, aver that any enterprises with a total capital employed not less than N1.5 million but not exceeding N200 million, including working capital, but excluding the cost of land and/or with a staff strength of not less than ten and not more than 300 can be described as a Small and Medium Scale Enterprise. Kozak (2007) argues that the best way to describe SMEs is that they are companies with metrics, usually the number of employees or annual turnover below a certain threshold. These indicators, numbers of employees and/or turnover rate, tend to define the context within which different countries and economies situate their understanding of small and medium scale enterprises. It is to say that even though SMEs are definable with much or less the same indicator (numbers of employees, rate of turnover etc.), the indicators are not the same in all countries. In other words, the number of employees and the total amount of turnover for defining SMEs in different countries is undoubtedly not the same.

\subsection{Theoretical Analysis: Social learning theory}

One of the most cited and reviewed theories in the discourse on entrepreneurial mentoring is the social learning theory, which is a potent and popular theory that efficiently describes how individuals acquire skills and competencies that can facilitate their work process (Bandura, 1976). Bandura (1997) posits that the learning process would be complicated if people had to rely solely on the effects of their own actions to inform them on what to do. The social learning theory's thrust lies in its emphasis for the part played by models and mentors in transmitting specific behavior, attitudes, and emotional responses in different circumstances to mentees and proteges, indicating that there is much more to learn through role modeling than classical or operant conditioning. Role models, no doubt, play a pivotal role in shaping mentees' behavior who emulate their way of discharging duties and responsibilities, thereby influencing the work culture and ethics. Social learning theory typically explains that people learn new behaviour through observational learning, suggesting that if the mentee observes pleasant, favourable outcome or consequences in the observed behavior of the mentor, there is a tendency and high degree that the mentee will most likely imitate, and adopt the behavior of such mentors. The implication of this is that when mentees observe the behavior of role models who are their mentors, they can learn their behavioral patterns. Every individual at one time or the other has watched and tried to imitate the actions of others while performing a task (Bandura, 1997).

\subsection{Empirical Review}

Saara (2014) conducted a study titled on the influence of mentoring on a young manager. The purpose of the study was to examine the effects of mentoring on a young manager. In addition, the intention was to write about the theory of mentoring because it is still quite an unfamiliar subject and the aim was to increase its awareness. In the theory part of the study the main issue was to gather information about the theory of mentoring. Based on the findings it was possible to identify several positive and negative effects that mentoring has on a young manager, and the other research questions of the study were covered. This result also supported 
the author's own experience about mentoring. The differences between theoretical and empirical findings concerned the internal and external effects. Literature emphasized the external effects such as salary and promotion and interviewees emphasized the internal effects such as self-confidence and personal development. Anyone who considers taking part in a mentorship program can utilize the results of this study and think whether this is the right tool for him/her or not. Davies (2016) conducted a study titled Formal Mentorship and Entrepreneurial Learning: The case of a support program in Western Cape Clothing Sector. The objective of the study was to examine the impact of formal mentorship on entrepreneurial learning since past research does not adequately address entrepreneurial learning in the context of prolonged turbulent competitive environments, and the role of formal mentorship as a significant contributor to entrepreneurial learning. This qualitative case study is set within the clothing industry of the Western Cape, which is affected by high levels of competitive turbulence. Entrepreneurs and their mentor's accounts are collected through unstructured and semi-structured personal interviews and analyzed using thematic analysis. The mentors are contracted to an organization that provides business development support to SMEs within the clothing sector. Key participants within this organization, and their sponsor were interviewed to study strategic influences on formal mentorship. This constitutes the case and a purposive-snowball sampling strategy was employed.

The research shows how strategic sponsorship agreements influence the functions and roles that mentors adopt within a top-down approach to mentoring. Findings revealed that formal mentorship provides a valuable intervention as a training mechanism in the SME sector, a propensity for technically driven mentoring outcomes is specific to the clothing industry case. While entrepreneurial learning is associated with formal mentorship, it does not necessarily influence business innovation. Crompton (2016) carried out research that sought to investigate the effect of business coaching and mentoring on Small-to-medium enterprise performance and growth. The aim of the research was to identify the impacts of business coaching on firm revenue performance and percentage growth. The research design was exploratory. The study adopted a mixed method that combines qualitative and quantitative research. Descriptive and inferential statistics were used. The data analysis findings indicated that business coaching via mentoring significantly assists in supporting the growth and development of SMEs. Uma, Onwusogbolu and Obidike (2016) conducted research investigating the relationship between mentorship and entrepreneurship and their contribution to his development of Nigeria. The study was based on an extant review of the literature. The systematic review of the literature revealed that formal and informal mentoring and entrepreneurship have many advantages, which are indispensable sources of cheap continual education that have assisted in repositioning and accelerating effective resource allocation and utilization. Various economic theories support improving human quality through mentoring and entrepreneurship.

\section{Methodology}

The descriptive survey research design was adopted for this study. This method was appropriate for this study because it will help the researcher to discover relative incidence and distribution on the population. The population of the study comprises 103(One hundred and three) SMEs. This figure coincided with the statistics of SMEs that have been registered with the National Association of Small and Medium Enterprises (NASMEs) in Kwara Central Senatorial district comprising Ilorin West, Ilorin East, Ilorin South and Asa Local Government Areas and had been active since the past five years (2015-2019). A sample size of 82 (EightyTwo) respondents was arrived at using Guilford and Flusher (1973) formulae. Data was gathered using primary sources of data, the questionnaire was used as a research instrument for data collection in this study, and the researcher utilized oral interview Quantitative method of data analysis. Data collected were coded and analyzed with a descriptive statistics frequency table, simple percentage, while inferential statistics of Analysis of Variance (ANOVA) was used to test the formulated hypothesis.

\section{Results and Discussion of Findings}

\section{Test of Hypothesis I}

$\boldsymbol{H}_{\text {oI: }}$ : Psychosocial mentoring support does not significantly relate to performance of SMEs in Kwara State.

Table 1. Analysis of Variance the relationship between psychosocial mentoring support and organizational performance

\begin{tabular}{|l|c|c|c|c|c|}
\hline Source & SS & df & MS & F & Prob> F \\
\hline Between groups & 33.57 & 2 & 16.79 & 89.32 & 0.0000 \\
\hline Within groups & 7.71 & 80 & .089 & & \\
\hline Total & 41.28 & 82 & .46 & & Prob>chi2 $=0.001$ \\
\hline Bartlett's test for equal variances: & \multicolumn{2}{|l|}{ chi2(3)=2.92 } \\
\hline
\end{tabular}

Source: Researcher's Analysis (2019) using STATA 11. (Statistically significant at 5\%) 
The table above shows the relationship between psychosocial mentoring support and SMEs performance using one-way ANOVA. Analysis of data showed that the P-value is less than 0.05 ; the null hypothesis is rejected while the alternate hypothesis is accepted. Hence, psychosocial mentoring supports have a significant relationship with SMEs performance. It is in line with the previous studies of Crompton (2016) and Chebii (2017) whose findings also indicated that there is a significant relationship between psychosocial mentoring support and SMEs performance.

\section{Test of Hypothesis II}

$\boldsymbol{H}_{\boldsymbol{2} 2}$ : Career mentoring support does not significantly relate to performance of SMEs in Kwara State.

Table 2. Analysis of Variance the relationship between career mentoring support and organizational performance

\begin{tabular}{|l|c|c|c|c|c|}
\hline Source & SS & df & MS & F & Prob> F \\
\hline Between groups & 34.57 & 3 & 16.79 & 97.12 & 0.0000 \\
\hline Within groups & 6.71 & 79 & .09 & & \\
\hline Total & 41.28 & 82 & .82 & & Prob>chi2 $=0.000$ \\
\hline Bartlett's test for equal variances: & \multicolumn{2}{|l|}{ chi2(3)=4.11 } \\
\hline
\end{tabular}

Source: Researcher's Analysis (2019) using STATA 11. (Statistically significant at 5\%)

The table above shows the relationship between career mentoring support and SMEs performance using oneway ANOVA. Analysis of data showed that the P-value is less than 0.05 ; the null hypothesis is rejected while the alternate theory is accepted. Hence, career mentoring supports have a significant relationship with SMEs performance. It is in line with the previous studies of 'Crompton (2016) and Chebii (2017), whose findings also indicated significantly.

\section{Test of Hypothesis III}

$\boldsymbol{H}_{\text {o3: }}$ Role modelling support does not have any significant impact on SMEs performance.

Table 3. Analysis of Variance the relationship between career mentoring support and organizational performance

\begin{tabular}{|l|c|c|c|c|c|}
\hline Source & SS & df & MS & F & Prob> F \\
\hline Between groups & 24.89 & 2 & 24.89 & 73.62 & 0.0000 \\
\hline Within groups & 16.40 & 80 & .19 & & \\
\hline Total & 41.29 & 82 & .46 & & Prob>chi2 $=0.000$ \\
\hline Bartlett's test for equal variances: & chi2(3)=6.77 & & \\
\hline
\end{tabular}

Source: Researcher's Analysis (2019) using STATA 11. (Statistically significant at 5\%)

The table above shows the relationship between Role modeling mentoring support and SMEs performance using one-way ANOVA. Analysis of data showed that the P-value is less than 0.05; the null hypothesis is rejected while the alternate theory is accepted. Hence, Role modeling mentoring supports have a significant relationship with SMEs performance. This is in line with the previous studies of Crompton (2016) and Chebii (2017) whose findings also indicated that there is a significant relationship between role modeling mentoring support and SMEs performance.

\section{Conclusion}

Mentoring is among the few tools used/needed for preparing tomorrows' skilled employees and is also used to strengthen organizational capabilities, intelligence, build organization knowledge, and sustain the organization's competitive advantage. The dynamic career environment heightens the need for entrepreneurs to engage other people in their career and personal development. These engagements, if done by entrepreneurial mentors, would be expected to result in entrepreneurial outcomes. Mentoring is an excellent forum for an individual to have an opportunity to obtain feedback regarding job performance needed to improve personal skills, thus broadening one's career development. Effective and efficient mentorship programs tend to raise entrepreneurial outcomes among upcoming entrepreneurs operating SMEs. Based on the findings of this study, it can be concluded that there is a significant relationship between psychosocial mentoring support and SMEs performance; there is also a significant relationship between career mentoring support and SMEs performance.

\section{Recommendations}

Based on the findings of the study, the following recommendations are proposed. SMEs owners must be steadfast in continuously providing personal counsel to their employees and protégés by relating them on a 
more personal level as this will stimulate and improve their personal development, building confidence, sense of competence, clarity of identity, and effectiveness in the job. SMEs owners must be steadfast in continuously providing sponsorship, coaching, exposure, visibility, protection and providing challenging assignments to their employees and protégés this will facilitate their business advancement pedagogy and promote the entrepreneurial outcome. SMEs owners must be steadfast in continuously providing succession planning for employees and protégés through classic mentoring. Thus, one-to-one interactive process of guided developmental learning where protégés have reasonably frequent contact and sufficient interactive time must be enshrined in the organization's culture.

Author Contribution. Conceptualization, Brimah Bolatito Amudat and Sheu Musa Olojeola; data curation, Rabiu Rukayat Oloruntoyin and Sheu Musa Olojeola; formal analysis, Rabiu Rukayat Oloruntoyin and Sheu Musa Olojeola; funding acquisition, Bamidele Ayodeji Gbenga and Rabiu Rukayat Oloruntoyin; investigation, Brimah Bolatito Amudat and Sheu Musa Olojeola; methodology, Brimah Bolatito Amudat and Rabiu Rukayat Oloruntoyin; project administration, Brimah Bolatito Amudat and Sheu Musa Olojeola; resources, Brimah Bolatito Amudat and Bamidele Ayodeji Gbenga; Software: Bamidele Ayodeji Gbenga and Rabiu Rukayat Oloruntoyin; supervision, Brimah Bolatito Amudat and Rabiu Rukayat Oloruntoyin; validation, Brimah Bolatito Amudat and Bamidele Ayodeji Gbenga; visualisation, Brimah Bolatito Amudat and Bamidele Ayodeji Gbenga; writing - original draft, Brimah Bolatito Amudat and Sheu Musa Olojeola; writing- review and editing, Bamidele Ayodeji Gbenga and Rabiu Rukayat Oloruntoyin.

Funding. This research was funded solely by the authors.

\section{References}

1. Adams, E. (2016). The influence of selected demographic variables on the experience of stress among first year students at a selected university in the Western Cape. Western Cape: University of the Western Cape. Available at: https://www.researchgate.net/publication/482219601.

2. Allen, T.D., \& Eby, L.T. (2003). Relationship effectiveness for mentors: Factors associated with learning and quality. Journal of Management, 29(4), 469-86. https://doi.org/10.1348/0144666001641102.

3. Allen, T.D., Eby, L.T., \& Lentz, F. (2006b). The relationship between formal mentoring program characteristics and perceived program effectiveness. Personnel Psychology, 59(1), 125-53. Available at: https://onlinelibrary.wiley.com/doi/abs/10.1111/j.1744-6570.2006.00747.x.

4. Allen, T.D., Day, R., \& Lentz, E. (2011). The role of interpersonal comfort in mentoring relationships. Journal of Career Development, 31(3), 155-169. https://doi.org/10.1118/014466600172937.

5. Arogundade, B.B. (2000). Entrepreneurship Education: An Imperative for Sustainable Development in Nigeria. Journal of Emerging Trends in Educational Research and Policy Studies (JETERAPS), 2(1), $26-29$. Available at: https://www.researchgate.net/publication.

6. Ayer, N. (2010). Learning from mentors: perspectives of South African entrepreneurs, Unpublished MBA dissertation, Pretoria: University of Pretoria, Retrieved from: http://upetd.up.ac.za/thesis/available/etd04042011-145446/.

7. Ayyagari, M.T. Beck and Demirguc-Kunt, A. (2003). Small and Medium Enterprises across the Globe. A New database. World Bank, Development Research Group. Working paper 3127 Washington DC. Available at: https://www.koganpage.com.

8. Boyd, J.H. (1998). Mentoring in family firms: A reflective analysis of senior executives' perceptions. Dissertation Abstracts International, 59(04), 1246. (UMI No. 9830821). Available at: https://www.academia.edu.

9. Bygrave, W. (1989). The entrepreneurship Paradigm (I): A philosophical look at its research methodologies. Entrepreneurship Theory and Practice, 1(1), 7-26. https://journals.sagepub.com/doi/10.1177/104225878901400102.

10.Crompton, B.M. (2016). The Effect of Business Coaching and Mentoring on Small-To-Medium Enterprise Performance and Growth. Unpublished thesis submitted in fulfillment of the requirements for the degree of Doctor of Philosophy School of Management College of Business RMIT University, Melbourne, Australia. Available at: https://docplayer.net/51820732-The-effect-of-business-coaching-and-mentoringon-small-to-medium-enterprise-performance-and-growth-bernadette-margaret-crompton.html.

11.Chebii, P.A. (2017). Entrepreneurial Mentoring and Its Outcomes AmongSmall and Medium Enterprises in Eldoret, UasinGishu County, Kenya. Jomo Kenyatta University of Agriculture and technology. Available at: http://ir.jkuat.ac.ke/handle/123456789/3433.

12.Clutterbuck, D. (2004). Everyone needs a mentor - Fostering talent in your organizations (4th ed.). London: CIPD. Available at: https://flylib.com/books/en/2.125.1.4/1/. 
13.Davies, C. (2016). Formal Mentorship and Entrepreneurial Learning the Case of a Support Programme in the Western Cape Clothing Sector. Mini-thesis summited in partial fulfillment of the requirements for the degree of Master of Commerce in the School of Business and Finance, University of the Western Cape. Faculty of Economic and Management Sciences. Available at: http://etd.uwc.ac.za/xmlui/handle/11394/5537.

14.GOK (2005). Sessional Paper No 2 on Development of Micro and Small Enterprises for Wealth and Employment Creation for Poverty Reduction. Government Printers, Nairobi. Available at: https://searchworks.stanford.edu/view/6369093.

15.Grace, T., \& Tomola, M. (2008). An empirical analysis of factors associated with the profitability of Small and Medium enterprises in Nigeria. African Journal of Business Management, 2(10), 195-200. Available at: https://EconPapers.repec.org/RePEc:eco:journ.

16. Guilford and Flusher (1973). Fundamental statistics in psychology education. McGrawill New York. 100-105. Available at: https://www.scribd.com/document.

17.IBA (2001). The Institute of Business Advisers South Africa. Membership Information 20/09/2001, ref S2L. Available at: https://ibasa.org.za/.

18.Kozak, R. (2007). Small and Medium Forest Enterprises: Instrument of change in the Developing World. Vancouver, British Colombia, University of British Columbia. Available at: https://citeseerx.ist.psu.edu/viewdoc/download?doi=10.1.1.494.9436\&rep=rep1\&type=pdf.

19.Kram, K.E. (1985). Mentoring at work: Developmental relationships in organizational life. Glenview: Scott Foresman. MindTools. A mutually beneficial partnership. Available at: http://www.mindtools.com/pages/article/newCDV 72.htm.

20.Mind Tools (2014). Mentoring. A mutually beneficial partnership. Available at: http://www.mindtools.com/pages/article/newCDV_72.htm.

21.McClelland, D.C. (1961). The Achieving Society. Van Nostrand, Reinhold. Available at: https://scholar.google.com/scholar?hl=en\&as sdt=0\%2C5\&q=McClelland\%2C\%09D.\%09C.\%09\%2819 61\%29.\%09The\%09Achieving\%09Society.\&btnG=.

22.Nnanna, O.J. (2002). Financing small business under the new CBN directive and its likely impact on industrial growth of the Nigerian economy. $C B N$ Bulletin, 25(3), 1-10. Available at: https://scholar.google.com/scholar?hl=en\&as_sdt=0\%2C5\&q=Nnanna\%2C+O.+J.+\%282002\%29.+Finan cing+small+business+under+the+new+CBN+directive+and+its+likely+impact.

23.Otokit, S.O. (1987). High Technology in Small Scale Industries: A Comparative Study of Nigeria and Industrized Countries. Ph.D. Thesis submitted to University of Delhi. Available at: https://www.academia.edu.

24.Rabiu, R. O., Olanipekun, W. D., Bamidele, A. G., Awe, O. I. (2020). Analysis of Factors Influencing Adoption of Human Resource Practices by Small and Medium Scale Enterprises in Nigeria. Business Ethics and Leadership, 4(2), 16-25. http://doi.org/10.21272/bel.4(2).16-25.2020.

25.Saara Hautala (2014). The Influence of Mentoring on a Young Manager. Saimaa University of Applied Sciences Faculty of Business Administration, Lappeenranta Degree Programme in International Business. Available at: https://scholar.google.com/scholar?cluster=7156145985145211938\&hl=en\&as_sdt=0,5.

26.Schumpeter, J.A. (1934). The theory of economic development, (vol. XLVI). Cambridge, MA: Harvard. Available at: https://scholar.google.com/scholar?hl=en\&as sdt=0\%2C5\&q=Schumpeter\%2C+J.+A.+\%.

27.Schumpeter, J.A. (1982). The Theory of Economic Development: An Inquiry into Profits Capital, Credit, Interest, and the Business Cycle. Piscataway, NJ: Transaction Publishers. Available at: https://www.hup.harvard.edu/catalog.php?isbn=9780674879904.

28.Timmons, J.A., \& Spinelli, S. (2004). New Venture Creation: Entrepreneurship for the 21st Century. Boston: McGraw Hill Irwin. Available at: https://pdfs.semanticscholar.org/.

29.Uma, K.E., Onwusogbolu, R.D., Obidike, P.C. (2015). A Review of Mentorship and Entrepreneurship: Impact on Nigeria's Economic Development. International Journal of Innovative Science, Engineering \& Technology, 2(9), 1-10. Available at: https://EconPapers.repec.org/RePEc:eco:journ. 